\title{
When is sensorimotor stroke a lacunar syndrome?
}

\author{
C Y HUANG, E WOO, Y L YU, F L CHAN* \\ From the Department of Medicine, University of Hong Kong and Radiodiagnostic Division, Queen Mary \\ Hospital,* Hong Kong
}

\begin{abstract}
SUMMARY Forty five patients with clear sensorium and no neurological deficits other than unilateral motor and sensory impairment underwent computed tomography (CT). Twenty patients had sensorimotor stroke with impairment of all sensory modalities (type 1). Eight had only impairment of nociceptive sensation (type 2) and 15 had only proprioceptive impairment (type 3 ). Two patients had sensory impairment in one limb only (type 4). Lacunes were found in patients in the first three groups. However, $80 \%$ of those who had hemiparesis and incomplete sensory loss were found to have a lacune or normal CT scan whilst only $33 \%$ of those with complete motor or sensory impairment had lacunes. It is proposed that sensorimotor stroke as a lacunar syndrome be best restricted to those with only mild to moderate hemiparesis and sensory impairment in both upper and lower limbs. The degree and extent of sensory and motor involvement may vary, however, possibly dependent on whether the thalamo-geniculate, anterior choroidal or lateral lenticulostriate artery is affected.
\end{abstract}

Mohr et $a l^{1}$ described in 1977 a case of thalamocapsular lacune which caused a dense sensorimotor stroke. Subsequently several other cases of sensorimotor stroke were reported. Nevertheless, the clinical features of sensorimotor stroke have not been well defined, and in a recent review ${ }^{2}$ Mohr has emphasised that "the rarity of these cases should set aside any causal assumption that small deep infarcts cause most instances of sensorimotor stroke". We report here our recent experience with this syndrome.

\section{Patients and method}

Forty five patients (20 males, 25 females, age 66 SD $6 \cdot 1$ years) were seen between April 1984 and February 1986 with a unilateral motor weakness involving face, arm and leg accompanied by sensory impairment but no other neurological deficit. In particular, they had normal alertness and mentation and did not have ataxia. They were classified into four types according to the nature of the sensory impairment:

Type 1: all sensory modalities affected,

Type 2: only nociceptive deficit present,

Type 3: only proprioceptive deficit present, and

Type 4: sensory impairment present in only one limb. Each type was further classified into A or B according to whether the motor or sensory deficit was complete or not:

Address for reprint requests: Dr C Y Huang, Department of Medicine, University of Hong Kong, Queen Mary Hospital, Pokfulam Road, Hong Kong.

Received 22 July 1986. Accepted 15 August 1986.
A: patients with submaximal motor and sensory impairment (with respect to motor impairment, this refers to MRC Grade 1 to 4 and is labelled as hemiparesis or monoparesis; with respect to sensory impairment, this refers to decreased sensation).

B: patients with either total paralysis (hemiplegia, monoplegia) or total sensory loss in at least one limb.

Computed tomography (CT) of the brain was obtained using a GE 9800 scanner with contiguous $10 \mathrm{~mm}$ thick slices. The examination was performed in the first week after the onset of symptoms in $49 \%$ of the patients, in the second to third week in $36 \%$ and more than 3 weeks in the remainder. The CT findings were classified as normal, lacune, infarct or haemorrhage. Lacune was defined as a hypodense area in the thalamo-capsular-corona radiata region with a lesion volume less than $4 \mathrm{ml}$. Those with larger volumes were classified as deep infarct. Volume was calculated according to the method of Nelson et al. ${ }^{3}$

\section{Results}

Type 1 (table 1): There were 20 patients with weakness and impairment of both proprioceptive and nociceptive sensation. Seven of these patients were classified as group B. Of these, only one (patient 18) had complete proprioceptive loss but mild hemiparesis, whereas two (patients 15,19 ) had complete proprioceptive loss and dense hemiplegia. The other four patients had a totally paralysed upper limb accompanied by varying degrees of sensory impairment. Only two of these seven patients had a lacune. Two patients had infarcts. Of the 13 patients in group A, 
When is sensorimotor stroke a lacunar syndrome?

Table 1 Clinical features in group 1 sensorimotor stroke

\begin{tabular}{|c|c|c|c|c|c|c|c|c|}
\hline & \multirow{2}{*}{$\begin{array}{l}\text { Sex/age } \\
(y r)\end{array}$} & \multicolumn{2}{|c|}{ Motor power* } & \multicolumn{2}{|c|}{ Proprioception } & \multicolumn{2}{|c|}{ Nociception } & \multirow[b]{2}{*}{ CT finding } \\
\hline & & $U L$ & $L L$ & $U L$ & $L L$ & $U L$ & $L L$ & \\
\hline $\begin{array}{l}\text { Type 1 } \\
1 \\
2 \\
3 \\
4 \\
5 \\
6 \\
7 \\
8 \\
9 \\
10 \\
11 \\
12 \\
13\end{array}$ & $\begin{array}{c}\text { Group } A \\
\text { M/58 } \\
\text { F/71 } \\
\text { F/72 } \\
\text { M/64 } \\
\text { F/66 } \\
\text { F/64 } \\
\text { F/65 } \\
\text { F/74 } \\
\text { F/75 } \\
\text { F/70 } \\
\text { F/48 } \\
\text { F/77 } \\
\text { M/67 }\end{array}$ & $\begin{array}{l}4 \\
4 \\
3 \\
2 \\
3 \\
2 \\
2 \\
4 \\
2 \\
3 \\
3 \\
3 \\
4 \\
2\end{array}$ & $\begin{array}{l}4 \\
3 \\
3 \\
2 \\
2 \\
3 \\
2 \\
4 \\
3 \\
2 \\
4 \\
4 \\
3 \\
3 \\
3\end{array}$ & $\begin{array}{l}\downarrow \\
\vdots \\
\vdots \\
\vdots \\
\vdots \\
\vdots \\
\vdots \\
\vdots \\
\vdots \\
\vdots \\
\vdots\end{array}$ & $\downarrow$ & $\begin{array}{l}\downarrow \\
\vdots \\
\vdots \\
\vdots \\
\vdots \\
\vdots \\
\vdots \\
\vdots \\
\vdots\end{array}$ & $\downarrow$ & $\begin{array}{l}\text { Normal } \\
\text { Normal } \\
\text { Anterior capsular lacune } \\
\text { Posterior capsular lacune } \\
\text { Posterior capsular lacune } \\
\text { Thalamocapsular lacune } \\
\text { Thalamocapsular lacune } \\
\text { Capsular corona radiata lacune } \\
\text { Capsular corona radiata lacune } \\
\text { Putaminal corona radiata lacune } \\
\text { Posterior capsular haemorrhage } \\
\text { Posterior capsular haemorrhage } \\
\text { Putaminal haemorrhage }\end{array}$ \\
\hline $\begin{array}{l}\text { Type 1 } \\
14 \\
15 \\
16 \\
17 \\
18 \\
19 \\
20\end{array}$ & $\begin{array}{c}\text { Group B } \\
\text { F/63 } \\
\mathbf{M} / 67 \\
\mathbf{M} / 66 \\
\mathbf{F} / 62 \\
\mathbf{M} / 61 \\
\mathbf{M} / 64 \\
\mathbf{F} / 70\end{array}$ & $\begin{array}{l}0 \\
0 \\
0 \\
0 \\
3 \\
0 \\
0\end{array}$ & $\begin{array}{l}3 \\
3 \\
0 \\
3 \\
3 \\
0 \\
3\end{array}$ & $\begin{array}{l}\downarrow \\
\downarrow \\
0 \\
\downarrow \\
0 \\
0 \\
\downarrow\end{array}$ & $\begin{array}{l}\downarrow \\
\mathbf{N} \\
0 \\
1 \\
0 \\
0 \\
\downarrow\end{array}$ & $\begin{array}{l}\downarrow \\
\downarrow \\
\downarrow \\
\downarrow \\
0 \\
\downarrow\end{array}$ & $\begin{array}{l}\downarrow \\
\downarrow \\
\downarrow \\
\downarrow\end{array}$ & $\begin{array}{l}\text { Posterior capsular lacune } \\
\text { Corona radiata lacune } \\
\text { Corona radiata infarct } \\
\text { Corona radiata infarct } \\
\text { Thalamocapsular haemorrhage } \\
\text { Thalamocapsular haemorrhage } \\
\text { Putaminal haemorrhage }\end{array}$ \\
\hline
\end{tabular}

*MRC grading.

For sensory examination: $N$, normal; $\downarrow$, decreased; 0 , absent.

Table 2 Clinical features in group 2 sensorimotor stroke

\begin{tabular}{|c|c|c|c|c|c|c|c|c|}
\hline & \multirow{2}{*}{$\begin{array}{l}\text { Sex/age } \\
(y r)\end{array}$} & \multicolumn{2}{|c|}{ Motor power* } & \multicolumn{2}{|c|}{ Proprioception } & \multicolumn{2}{|c|}{ Nociception } & \multirow[b]{2}{*}{$C T$ finding } \\
\hline & & $U L$ & $L L$ & $U L$ & $L L$ & $U L$ & $L L$ & \\
\hline $\begin{array}{l}\text { Type } 2 \\
1 \\
2 \\
3 \\
4 \\
5 \\
6\end{array}$ & $\begin{array}{c}\text { Group A } \\
\text { F/66 } \\
\mathbf{M} / 58 \\
\mathbf{M} / 63 \\
\mathbf{M} / 67 \\
\mathrm{M} / 67 \\
\mathbf{M} / 70\end{array}$ & $\begin{array}{l}3 \\
2 \\
4 \\
3 \\
3 \\
3\end{array}$ & $\begin{array}{l}3 \\
2 \\
4 \\
3 \\
3 \\
4\end{array}$ & $\begin{array}{l}\mathbf{N} \\
\mathbf{N} \\
\mathbf{N} \\
\mathbf{N} \\
\mathbf{N} \\
\mathbf{N}\end{array}$ & $\begin{array}{l}\mathbf{N} \\
\mathbf{N} \\
\mathbf{N} \\
\mathbf{N} \\
\mathbf{N} \\
\mathbf{N}\end{array}$ & $\downarrow$ & $\downarrow$ & $\begin{array}{l}\text { Normal } \\
\text { Posterior capsular lacune } \\
\text { Posterior capsular lacune } \\
\text { Posterior capsular lacune } \\
\text { Corona radiata lacune } \\
\text { Corona radiata lacune }\end{array}$ \\
\hline $\begin{array}{l}\text { Type } 2 \\
7 \\
8\end{array}$ & $\begin{array}{c}\text { Group B } \\
\text { M/76 } \\
\text { F/58 }\end{array}$ & $\begin{array}{l}\mathbf{0} \\
\mathbf{0}\end{array}$ & $\begin{array}{l}0 \\
0\end{array}$ & $\begin{array}{l}\mathbf{N} \\
\mathbf{N}\end{array}$ & $\begin{array}{l}\mathbf{N} \\
\mathbf{N}\end{array}$ & $\begin{array}{l}1 \\
0\end{array}$ & $\frac{1}{0}$ & $\begin{array}{l}\text { Corona radiata infarct } \\
\text { Brainstem infarct }\end{array}$ \\
\hline
\end{tabular}

*MRC grading.

For sensory examination: $\mathbf{N}$, normal; $\downarrow$, decreased; $\mathbf{0}$, absent.

Table 3 Clinical features in groups 3 and 4 sensorimotor stroke

\begin{tabular}{|c|c|c|c|c|c|c|c|c|}
\hline & \multirow{2}{*}{$\begin{array}{l}\text { Sex/age } \\
(y r)\end{array}$} & \multicolumn{2}{|c|}{ Motor power } & \multicolumn{2}{|c|}{ Proprioception } & \multicolumn{2}{|c|}{ Nociception } & \multirow[b]{2}{*}{$C T$ finding } \\
\hline & & $U \boldsymbol{L}$ & $L L$ & $U L$ & $L L$ & $U L$ & $L L$ & \\
\hline $\begin{array}{l}\text { Type } 3 \\
1 \\
2 \\
3 \\
4 \\
5 \\
6 \\
7 \\
8 \\
9\end{array}$ & $\begin{array}{c}\text { Group A } \\
\text { M/70 } \\
\text { F/67 } \\
\text { F/67 } \\
\text { F/68 } \\
\text { M/68 } \\
\text { M/68 } \\
\text { M/61 } \\
\text { F/79 } \\
\text { M/70 }\end{array}$ & $\begin{array}{l}3 \\
2 \\
3 \\
3 \\
3 \\
4 \\
3 \\
1 \\
3\end{array}$ & $\begin{array}{l}3 \\
3 \\
4 \\
3 \\
3 \\
5 \\
3 \\
3 \\
3 \\
3\end{array}$ & $\begin{array}{l}\downarrow \\
\vdots \\
\vdots \\
\vdots \\
\vdots \\
\vdots \\
\vdots\end{array}$ & $\begin{array}{l}\downarrow \\
\downarrow \\
\vdots \\
\vdots \\
\vdots \\
\downarrow \\
\downarrow\end{array}$ & $\begin{array}{l}\mathbf{N} \\
\mathbf{N} \\
\mathbf{N} \\
\mathbf{N} \\
\mathbf{N} \\
\mathbf{N} \\
\mathbf{N} \\
\mathbf{N} \\
\mathbf{N}\end{array}$ & $\begin{array}{l}\mathbf{N} \\
\mathbf{N} \\
\mathbf{N} \\
\mathbf{N} \\
\mathbf{N} \\
\mathbf{N} \\
\mathbf{N} \\
\mathbf{N} \\
\mathbf{N}\end{array}$ & $\begin{array}{l}\text { Normal } \\
\text { Normal } \\
\text { Normal } \\
\text { Normal } \\
\text { Posterior capsular lacune } \\
\text { Thalamocapsular lacune } \\
\text { Corona radiata lacune } \\
\text { Corona radiata lacune } \\
\text { Putaminal haemorrhage }\end{array}$ \\
\hline $\begin{array}{l}\text { Type } 3 \\
10 \\
11 \\
12 \\
13 \\
14 \\
15\end{array}$ & $\begin{array}{l}\text { Group B } \\
\text { F/59 } \\
\text { F/74 } \\
\text { M/58 } \\
\text { F/61 } \\
\text { F/61 } \\
\text { F/58 }\end{array}$ & $\begin{array}{l}0 \\
0 \\
0 \\
0 \\
0 \\
0\end{array}$ & $\begin{array}{l}\mathbf{0} \\
\mathbf{3} \\
\mathbf{0} \\
\mathbf{3} \\
\mathbf{3} \\
\mathbf{0}\end{array}$ & $\begin{array}{l}\downarrow \\
\vdots \\
\vdots \\
0 \\
\downarrow \\
\downarrow\end{array}$ & $\begin{array}{l}\downarrow \\
\vdots \\
0 \\
0 \\
\downarrow \\
\downarrow\end{array}$ & $\begin{array}{l}\mathbf{N} \\
\mathbf{N} \\
\mathbf{N} \\
\mathbf{N} \\
\mathbf{N} \\
\mathbf{N}\end{array}$ & $\begin{array}{l}\mathbf{N} \\
\mathbf{N} \\
\mathbf{N} \\
\mathbf{N} \\
\mathbf{N} \\
\mathbf{N}\end{array}$ & $\begin{array}{l}\text { Posterior capsular lacune } \\
\text { Posterior capsular lacune } \\
\text { Corona radiata lacune } \\
\text { Corona radiata infaret } \\
\text { Striatocapsular infarct } \\
\text { Brainstem infarct }\end{array}$ \\
\hline $\begin{array}{c}\text { Type 4 } \\
1 \\
2\end{array}$ & $\begin{array}{l}\mathrm{F} / 70 \\
\mathbf{M} / 57\end{array}$ & $\begin{array}{l}2 \\
3\end{array}$ & $\begin{array}{l}3 \\
3\end{array}$ & $\underset{\mathbf{N}}{\mathbf{N}}$ & $\underset{\mathbf{N}}{\mathbf{N}}$ & $\downarrow$ & $\underset{\mathbf{N}}{\mathbf{N}}$ & $\begin{array}{l}\text { Brainstem infarct } \\
\text { Brainstem haemorrhage }\end{array}$ \\
\hline
\end{tabular}

*MRC grading.

For sensory examination: $N$, normal; $\downarrow$, decreased; 0 , absent. 


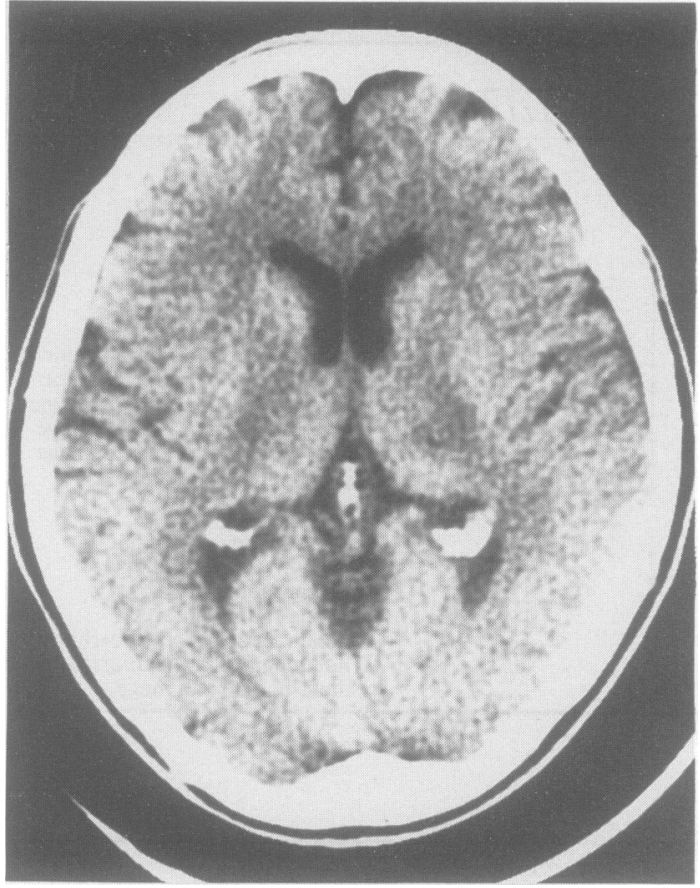

Fig 1 Left thalamocapsular lacune causing type $1 \mathrm{~A}$ sensorimotor stroke: right hemiparesis with decreased proprioception and nociception. (In all figs, left side is shown on the left.)

a lacune was seen in eight, being present in the thalamocapsular, capsular or corona radiata region. Two patients had a normal scan.

Type 2 (table 2): Group A: six patients had hemiparesis accompanied by decreased nociceptive sensation but normal proprioceptive sensation. Five of these had a capsular or corona radiata lacune and one had a normal CT scan.

Group B: two patients had hemiplegia with impairment of nociceptive sensation, and both had an infarct, one in the corona radiata and one in the brainstem.

Type 3 (table 3): Group A: nine patients had hemiparesis or monoparesis with impaired proprioceptive sensation but normal nociception. Four of these had lacunes, four had normal CT scans.

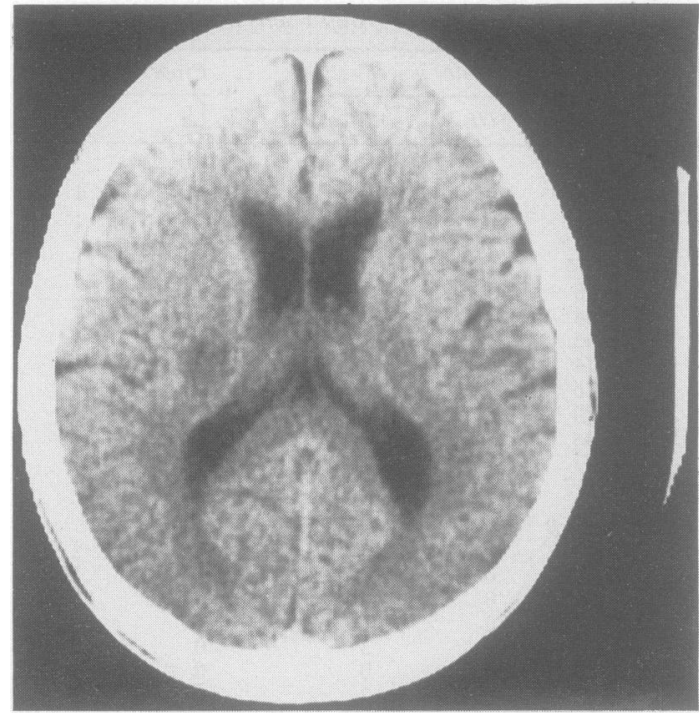

Fig 2 Right posterior capsular lacune causing type IB sensorimotor stroke: left hemiparesis with decreased proprioception and absent nociception.

Group B: monoplegia of the upper limb was found in three cases and hemiplegia in another three patients. Three of these six cases were due to a lacune Type 4 (table 3): Two patients had hemiparesis with partial nociceptive deficit in the upper limb only and normal proprioceptive sensation and were therefore classified group A. A brainstem lesion was present in both.

A lacune may be seen in types 1,2 or 3 of sensorimotor stroke (figs 1, 2). Of these lacunes $77.3 \%$ (17 out of 22, table 4) caused hemiparesis with incomplete sensory impairment (group A). Normal CT scans were seen in seven cases, none of which had severe sensory or motor impairment. Larger ischaemic lesions in the brainstem (fig 3 ) or the deep white matter (figs 4, 5) were found in eight cases of which only one had mild hemiparesis and sensory impairment, and the rest having hemiplegia or severe sensory deficits. Haemorrhage was found only in type 1,3 or 4 sensorimotor stroke and four of them were clinically indistinguishable from lacune (fig 6). None of the two

Table 4 CT findings in sensorimotor stroke

\begin{tabular}{|c|c|c|c|c|c|c|c|c|}
\hline & & \multicolumn{2}{|c|}{ Type 1} & \multicolumn{2}{|c|}{ Type 2} & \multicolumn{2}{|c|}{ Type 3} & \multirow{2}{*}{$\frac{\text { Type 4 }}{G p A}$} \\
\hline & & $G p A$ & $G p B$ & $G p A$ & $G p B$ & $G p A$ & $G p B$ & \\
\hline \multirow[t]{2}{*}{$\begin{array}{l}\text { Normal } \\
\text { Lacune } \\
\text { Infarct } \\
\text { Haemorrhage }\end{array}$} & $\begin{array}{r}(7) \\
(22) \\
(8) \\
(8)\end{array}$ & $\begin{array}{l}2 \\
8 \\
0 \\
3\end{array}$ & $\begin{array}{l}0 \\
2 \\
2 \\
3 \\
\end{array}$ & $\begin{array}{l}1 \\
5 \\
0 \\
0\end{array}$ & $\begin{array}{l}0 \\
0 \\
2 \\
0\end{array}$ & $\begin{array}{l}4 \\
4 \\
0 \\
1\end{array}$ & $\begin{array}{l}0 \\
3 \\
3 \\
0\end{array}$ & $\begin{array}{l}0 \\
0 \\
1 \\
1 \\
\end{array}$ \\
\hline & & 13 & 7 & 6 & 2 & 9 & 6 & 2 \\
\hline
\end{tabular}




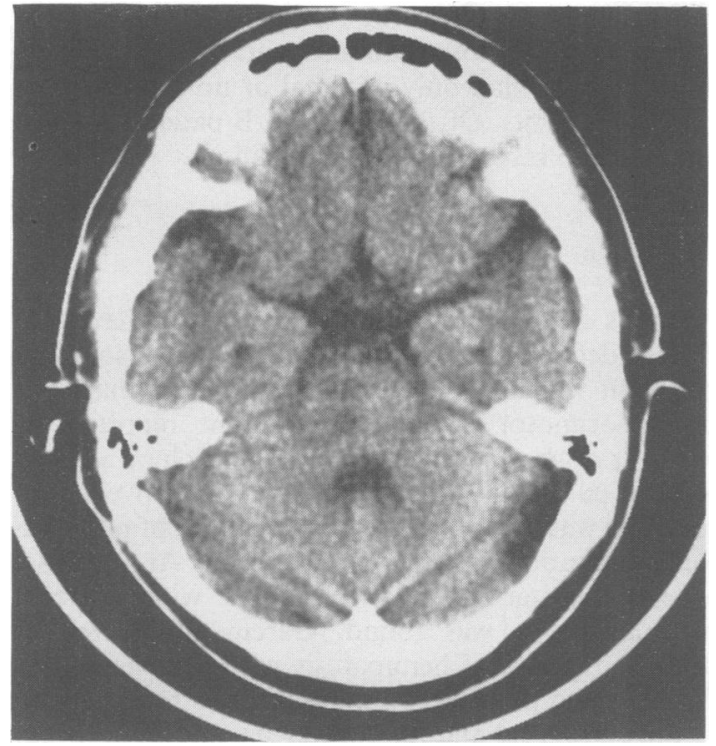

Fig 3 Right brainstem infarct causing type $3 B$ sensorimotor stroke: left hemiplegia with proprioceptive impairment but normal nociception.
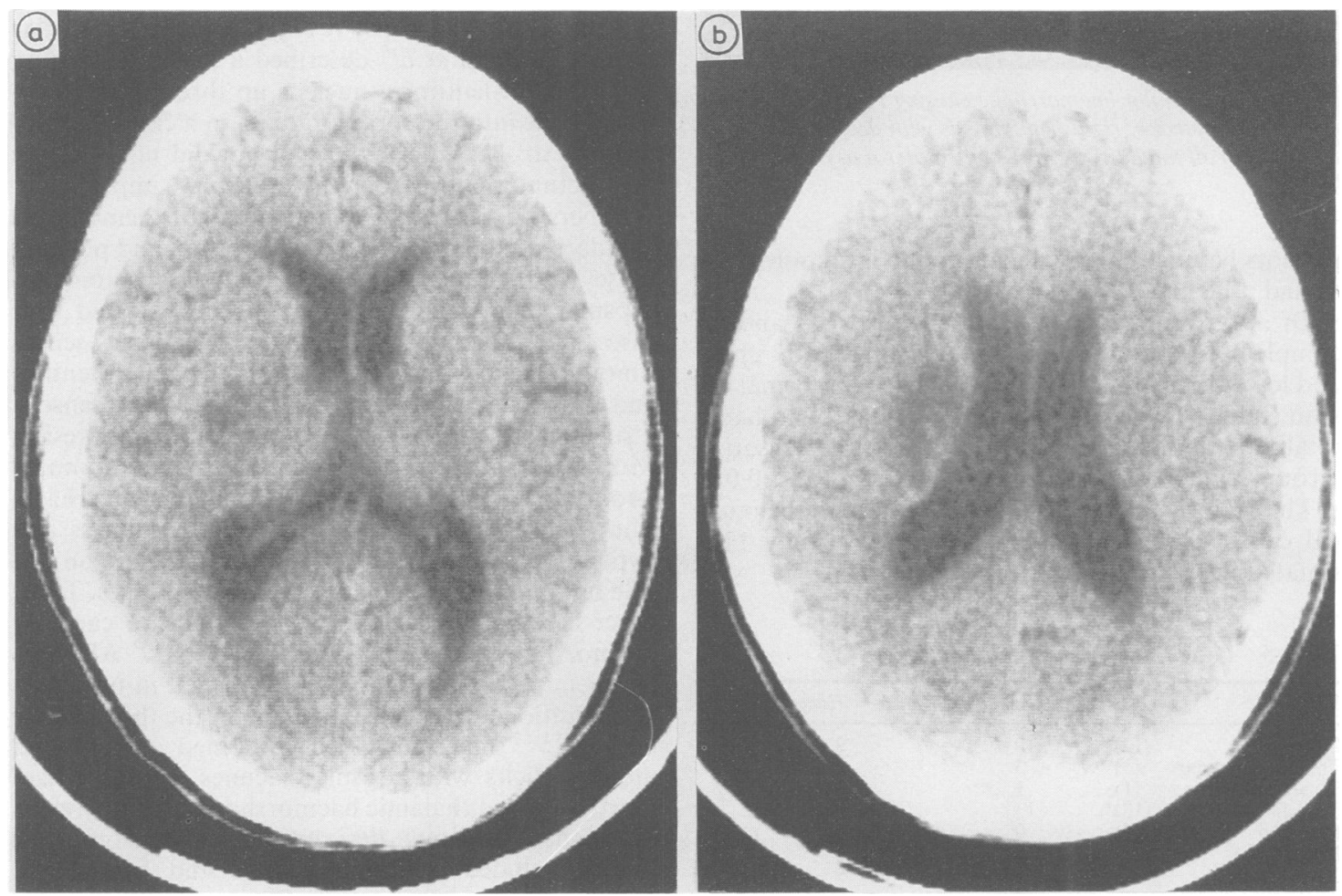

Fig 4 Right putamino-corona radiata infarct causing type $1 B$ sensorimotor stroke: left hemiplegia with absent proprioception and decreased nociception.

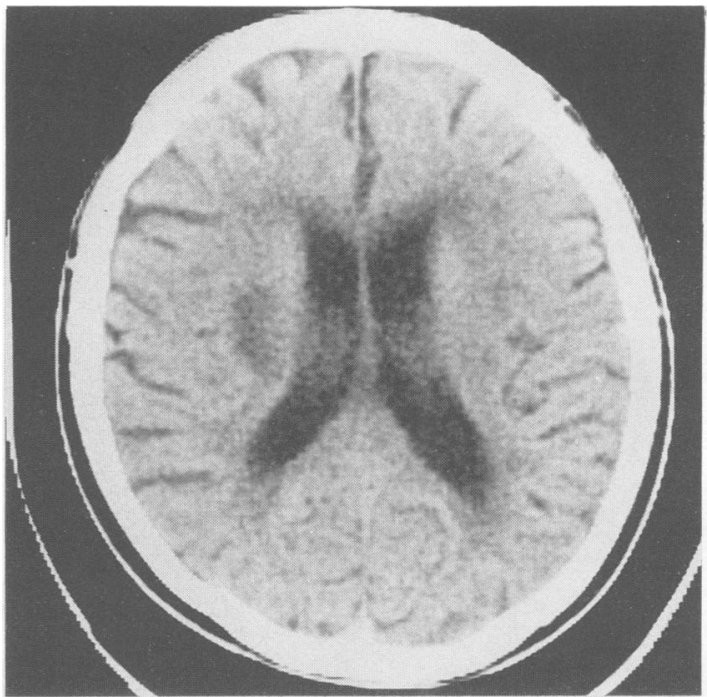

Fig 5 Right corona radiata infarct causing type $2 B$ sensorimotor stroke: dense left hemiplegia with decreased nociception but normal proprioception.

뭉

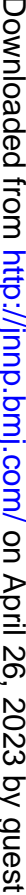




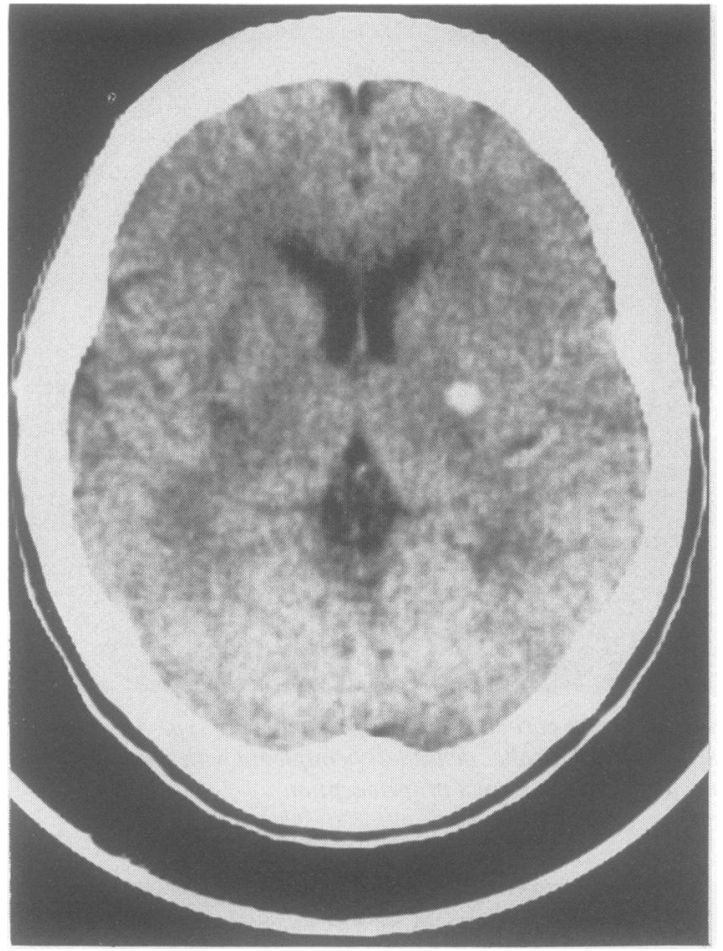

Fig 6 Left capsular haemorrhage causing type $1 A$ sensorimotor stroke: right hemiparesis with decreased sensation in all modalities. Note contralateral asymptomatic lacune.

patients having sensory deficit in one limb only (type 4) had a lacune.

Of 30 group A patients with hemiparesis and in. complete sensory impairment affecting both upper and lower limbs, $24(80 \%)$ had a lacune or normal CT scan (table 4 ) whereas only $33 \%$ of those who had a totally paralysed limb or severely impaired sensation (group A) had a lacune or a normal scan ( $<<0.01)$.

The majority of the lesions were found in the internal capsular/corona radiata region, with only $11 \%$ situated in the brainstem (table 5).

Table 5 Lesion site in sensorimotor stroke

\begin{tabular}{lccl}
\hline Site & & Ischaemia & Haemorrhage \\
\hline Capsular & $(12)$ & 10 & 2 \\
Thalamocapsular & $(5)$ & 3 & 2 \\
Striatocapsular & $(1)$ & 1 & 0 \\
Corona radiata & (13)* & 13 & 0 \\
Putamen & $(3)$ & 0 & 3 \\
Brainstem & $(4)$ & 3 & 1 \\
\cline { 2 - 4 } & & 30 & 8 \\
\hline
\end{tabular}

*Including two cases of capsular-corona radiata lacune, and one case of putamino-corona radiata lacune.
Thirty patients ( 20 group A, 10 group B) have been followed.up for more than one year. Of the 20 group A patients, 15 had only minimal or no residual neurological deficits. Of the $\mathbf{1 0}$ group B patients six had moderate to severe neurological deficits.

\section{Discussion}

Previous reports of sensorimotor stroke have not clearly defined the extent of motor or sensory impairment which qualifies for or excludes a diagnosis of sensorimotor stroke. The patient reported by Mohr et al ${ }^{1}$ had severe hemiparesis which progressed to total paralysis and then gradually improved. Sensory loss was severe with no appreciation of pinprick, touch, vibration, or passive movements. At necropsy, a ventro-posterior thalamic lacune with adjacent capsular pallor was found. Garcin and Lapresle ${ }^{4}$ described a case of hemiparesis with decreased temperature and pain sensation and dysaesthesia limited to the peribuccal and forearm areas, and at necropsy a small lacune at the ventro-posterolateral and medial thalamic nuclei was found. Sunohara $e t a l^{5}$ described a case with hemiparesis and loss of all sensory modalities who later developed involuntary movements of the lower limb. Necropsy revealed a thalamocapsular lacune. Donnan et $a l^{6}$ described a lacune extending from the left lentiform nucleus up through the junctional zone into the corona radiata in a case of sensorimotor stroke with hemiplegia but did not describe the actual nature of the sensory impairment Weisberg ${ }^{7}$ described eight patients with hemiparesis and decreased pinprick, touch, vibration and position? sense who had lacunes in the caudato-putaminalcapsular regions. Robinson $e t a l^{8}$ investigated four cases of thalamocapsular lacunes causing sensorimotor stroke with somatosensory evoked potentials and described the deficits as "thalamic type sensory disturbance with a mild and transient hemiparesis". Mori et $a l^{9}$ also described seven cases of sensorimotor stroke due to capsular or putaminal haemorrhage. They defined sensorimotor stroke as weakness and hypoaesthesia involving the face, arm and leg on one side but did not give details in individual cases. Three other cases of sensorimotor stroke due to capsular haemorrhages have also been described. ${ }^{10}$ All three had hemiparesis, with nociceptive deficit in two cases and additional proprioceptive loss in the third. Other authors ${ }^{1112}$ have described combined sensory and motor deficits with capsular lacunes, capsular haemorrhages and thalamic haemorrhages. It is therefore clear that previous descriptions of sensorimotor stroke included both hemiparesis and hemiplegia, with sensory impairment of either one or more modalities and severity ranging from mild to dense. The anatomical extent of the impairment was mostly face, 
arm and leg but Garcin and Lapresle's case had sensory impairment limited to the peribuccal and forearm areas. ${ }^{4}$ Whilst the three necropsy cases ${ }^{145}$ all showed lesions in the thalamic sensory nuclei, the CT studies in recent series have shown lesions in the thalamus, thalamocapsular, corona radiata and caudato-putamino-capsular region. In the present series $89.4 \%$ of the lesions were situated in the thalamocapsular-corona radiata region, or the adjacent putamen. In addition, as haematomas and other pathologies have been reported to mimic pure motor hemiparesis and other lacunar syndromes, it would not be unexpected that when appropriately situated they can produce sensorimotor stroke as well.

The present series confirmed the previous findings in that lacunes can cause a sensorimotor stroke. In addition it is clear that the degree of motor weakness can vary from mild hemiparesis to hemiplegia, and the sensory impairment can vary from selective involvement of just the nociceptive, the proprioceptive, or all modalities of sensation. Overall, $64 \%$ of all sensorimotor strokes were found to have a normal scan or a lacune. However, if only hemiparesis with decreased sensation (group A patients) were considered as possible lacunar syndromes then $80 \%$ would be found to have a normal CT scan or a lacune, whereas only $33 \%$ of those with severe motor or sensory deficits (group B patients) would have a lacune or normal CT. Furthermore, the good long-term prognosis of our group A patients compared with the unfavourable outcome of our group B patients would support the concept that sensorimotor stroke with submaximal deficit is consistent with a lacunar syndrome. Although Mohr has reservations about whether sensorimotor stroke could be classified as a lacunar syndrome, ${ }^{2}$ our findings would favour the affirmative, but with the qualification that it is best restricted to those sensorimotor stroke with submaximal motor and sensory impairment in both upper and lower limbs.

There is no universal agreement on what constitutes a lacune on CT. In this study we have elected to restrict the term to those ischaemic lesions in the deep regions of the brain with volume of less than $4 \mathrm{ml}$. The five patients with lesions volume of $4 \cdot 7-7.8 \mathrm{ml}$ in the corona radiata and striatocapsular region designated had deep infarcts which could have otherwise been called super lacunes or giant lacunes. If they were also called lacunes then $75.5 \%$ of sensorimotor stroke would be due to lacunar infarction, and a more liberal definition can be used, with the understanding that group B patients are more likely to harbour larger lesions. It is unclear, however, whether such larger subcortical lesions typically result in classical lacunar syndromes or are necessarily always due to penetrating artery disease. ${ }^{1415}$ Furthermore, these larger infarcts are associated in our cases with a more severe clinical picture and less favourable outcome. We therefore prefer to restrict for the time being both the terms lacune and sensorimotor stroke.

The exact course of thalamocortical sensory projection is unknown in humans or animals. Groothuis et al $^{13}$ described a case of posterior capsular haemorrhage which caused impaired pinprick, vibration, and possibly also position sense. Touch remained normal. Pinprick, temperature, vibration, proprioceptive and touch sensation were impaired separately or together in capsular and corona radiata infarcts. ${ }^{1617}$ With parietal lesions, a variety of sensory disturbances have been recorded, including absence of all sensation, ${ }^{18}$ anaesthesia only, ${ }^{19}$ decreased touch sensation associated with hyperpathia ${ }^{20}$ and a pseudothalamic syndrome. ${ }^{21}$ Pure sensory stroke have also been described with a parietal lesion causing impaired joint position sense with astereognosis and poor two-point discrimination, but normal pinprick, touch, temperature and vibration detection. ${ }^{22}$ Thus selective impairment of either nociceptive or proprioceptive sensation in the company of motor weakness can result from lesions of the sensory pathway in the brainstem, thalamus, internal capsule, corona radiata, or parietal lobe.

The occurrence of sensorimotor stroke brings into question the vascular supply of the motor and sensory pathways. The ventrolateral thalamic nucleus receives its blood supply from both the thalamoperforate arteries which originate from the posterior cerebral artery as well as the thalamogeniculate branches from the posterior communicating arteries. ${ }^{23}$ The thalamogeniculate arteries also appear to supply part of the posterior limb of the internal capsule and occlusion of this vessel can give rise to both motor and sensory impairment. $^{24}$

The lenticulostriate branches of the middle cerebral artery on the other hand rarely vascularise the thalamus but regularly supply the dorsal aspect of the internal capsule. ${ }^{25}$ The inferior aspect of the internal capsule receives its blood supply from the anterior choroidal artery which also contributes to vascularisation of the thalamus via cisternal perforators and vessels from its plexal portion. ${ }^{23}$ Thus it would appear possible for a sensorimotor stroke to occur as a result of occlusion of either the thalamogeniculate or anterior choroidal arteries leading to ischaemia in the thalamus and internal capsule. It may be expected however that involvement of the former will lead to prominent sensory disturbance with minimal hemiparesis whilst with the latter, motor weakness predominates with sensory disturbance remaining mild. Such speculation appears consistent with recent descriptions of clinical deficits following occlusion of these vessels. ${ }^{26} 27$ In addition, putamino-corona radiata infarction resulting from occlusion of a lateral len- 
these vessels. ${ }^{26} 27$ In addition, putamino-corona radiata infarction resulting from occlusion of a lateral lenticulostriate artery apparently can also cause sensory and motor disturbance at a site distal to the thalamus (fig 4). Although not seen in this study, theoretical consideration would suggest also that a type $3 \mathrm{~A}$ sensorimotor stroke may result from the occlusion of a paramedian penetrator causing a brainstem lacune. Consideration of the vascular anatomy thus supports the concept that sensorimotor stroke is a lacunar syndrome, but there is a variable degree of sensory and motor impairment depending on which penetrating artery is involved.

\section{References}

1 Mohr JP, Kase CS, Meckler RJ, Fisher CM. Sensorimotor stroke due to thalamocapsular ischemia. Arch Neurol 1977;34:739-41.

2 Mohr JP. Lacunes. Stroke 1982;13:3-11.

3 Nelson RF, Pullicino P, Kendall BE, Marshall J. Computed tomography in patients presenting with lacunar syndromes. Stroke 1980;11:256-61.

4 Garcin R, Lapresle J. Syndrome sensitif de type thalamique et a topographie cheiro-orale par lesion localisée dans le thalamus. Rev Neurol (Paris) 1954;90:124-9.

5 Sunohara N, Mukoyama M, Mano Y, Satoyoshi E. Action-induced rhythmic dystonia: an autopsy case. Neurology 1984;34:321-7.

6 Donnan GA, Tress BM, Bladin PF. A prospective study of lacunar infarction using computerized tomography. Neurology 1982;32:49-56.

7 Weisberg LA. Lacunar infarcts. Clinical and computed tomographic correlations. Arch Neurol 1982;39:37-40.

8 Robinson RK, Richey ET, Kase CS, Mohr JP. Somatosensory evoked potentials in pure sensory stroke and related conditions. Stroke 1985;16:818-23.

9 Mori E, Tabuchi M, Yamadori A. Lacunar syndrome due to intracerebral hemorrhage. Stroke 1985; 16:454-9.

10 Weisberg LA, Wall M. Small capsular hemorrhages. Clinical-computed tomographic correlations. Arch Neurol 1984;41:1255-7.

11 Lee KY, Lie SK, Chiang TR, Hung TP. Small intracerebral hemorrhage clinically simulating lacunar infarction. J Formosan Medical Association 1983; 82:993-1000.

12 Kashihara M, Matsumoto K. Acute capsular infarction.
Location of the lesions and the clinical features. Neuroradiology 1985;27:248-53.

13 Groothuis DR, Duncan GW, Fisher CM. The human thalamocortical sensory path in the internal capsule: evidence from a small capsular hemorrhage causing a pure sensory stroke. Ann Neurol 1977;2:328-31.

14 Bladin PF, Berkovic SF. Striatocapsular infarction: Large infarcts in the lenticulostriate arterial territory. Neurology 1984;34:1423-30.

15 Caplan L, Babikian V, Helgason C, Hier DB, DeWitt D, Patel D, Stein R. Occlusive disease of the middle cerebral artery. Neurology 1985;35:975-82.

16 Rosenberg N, Koller R. Computerized tomography and pure sensory stroke. Neurology 1981;31:217-20.

17 Huang CY, Lui FS. Ataxic-hemiparesis, localisation and clinical features. Stroke 1984;15:363-5.

18 Yarnell P, Melamed E, Silverberg R. Global hemianesthesia: a parietal perceptual distortion suggesting non-organic illness. J Neurol Neurosurg Psychiatry 1978;41:843-6.

19 Paillard J, Michel F, Stelmach G. Localization without content: a tactile analogue of "blind sight". Arch Neurol 1983;40:548-51.

20 Breuer AC, Cuervo H, Selkoe DJ. Hyperpathia and sensory level due to parietal lobe arteriovenous malformation. Arch Neurol 1981;38:722-4.

21 Lhermitte F, Desi M, Signoret JL, Deloche G. Aphasie kinesthetique associée à syndrome psuedothalamique Rev Neurol (Paris) 1980;136:675-88.

22 Derouesne C, Mas JL, Bolgert AF, Castaigne P. Puree sensory stroke caused by a small cortical infarct in the middle cerebral artery territory. Stroke 1984;15:660-2

23 Plets C, De Reuck J, Vander Ecken H, Van den Bergh R The vascularization of the human thalamus. Acta Neurol Belg 1970;70:687-770.

24 Takahashi S, Goto K, Fukasawa H, Kawata Y, Uemurac K, Yaguchi K. Computed tomography of cerebral in farction along the distribution of the basal perforating arteries. Radiology 1985;155:119-30.

25 Umansky F, Gomes FB, Dujovny M, et al. The perforating branches of the middle cerebral artery. A microanatomical study. $J$ Neurosurg 1985;62:261-8.

26 Graff-Radford NR, Damasio H, Yamada T, Eslinger PJ, Damasio AR. Nonhaemorrhagic thalamic infarction. Clinical, neuropsychological and electrophysiologica findings in four anatomical groups defined by computerized tomography. Brain 1985;108:485-516.

27 Takahashi S, Kawata Y, Uemura K. CT findings on anterior choroidal artery occlusion. Rinsho Hoshasen 1980;25:575-81. 